\title{
INVENTAR DIAGRAMAS PARA TRANSBORDAR O ARQUIVO QUE DELIMITA A DOCÊNCIA
}

\author{
Francieli Regina Garlet \\ Universidade Federal de Santa Maria, \\ Santa Maria, Rio Grande do Sul, Brasil \\ Marilda Oliveira de Oliveira \\ Universidade Federal de Santa Maria, \\ Santa Maria, Rio Grande do Sul, Brasil
}

\begin{abstract}
Resumo: A proposta deste texto é: pensar a docência a partir dos conceitos de "arquivo, diagrama e fora", o que nos sugere abordar uma docência que sempre escape e se diferencie de si mesma a cada encontro que a afeta em meio a suas andanças pela vida. A maneira com que esta escrita, dá-se desenvolve a partir de nossas andarilhagens, e do que nela encontramos, carregamos, e por vezes também perdemos. Dá-se a partir de afetos que nos disparam a pensar a docência desde outros lugares que não somente o de uma atuação docente. Deste modo, permeiam esta escrita algumas fotografias e uma experimentação artística, afetos que são convocados para dialogar com os conceitos de arquivo, diagrama e fora, produzindo a partir deste encontro, atravessamentos na docência, transbordando-a em outras direções.
\end{abstract}

Palavras-chave: Arquivo. Diagrama. Fora. Docência.

INTRODUÇÃO

Fotografias de casas abandonadas e a experimentação artística - 'Tentativa frustrada de cultivar transbordamentos'- se enleiam aqui aos conceitos de "arquivo", "diagrama"e "fora", pensados a partir de Foucault (2008), Deleuze (2006b) e Levy (2011) e movimentam o pensamento no que tange 
ao modo conforme nós produzimos docentes em meio às vivências, que não dizem somente a respeito de uma atuação docente. Abordar o modo como nos produzimos docentes, a partir desta perspectiva sugere pensar uma docência que se diferencia de si a cada vez, a cada encontro com o outro, a cada afeto em meio à vida.

Os elementos recolhidos de nossas vivências, que permeiam esta escrita são trazidos como disparadores, ou seja, não estão aqui de modo a reforçar a escrita ou ilustrá-la. Estes elementos (fotografias de casas abandonadas e a experimentação artística) estão aqui para dialogar com a escrita, para tensioná-la.

Ao mesmo tempo em que procuramos habitar o vazio que se instala entre estes elementos de nossas vivências e os conceitos que operamos na pesquisa de modo a pensar a docência, intentamos deixar brechas para que o próprio leitor também possa (a sua maneira) habitá-lo, e inventar assim outras relações e possibilidades.

A problemática que recolhe e emaranha estes elementos aos conceitos de arquivo, diagrama e fora, movendo esta escrita, é disparada pelo questionamento: Como varrer a figuração docente e fazer surgir dela uma outra forma, de natureza diferente, que intervenha no que é costumeiro e a faça transbordar em outras direções? Propusemo-nos, então, nesta escrita, varrer uma figuração docente, entendida aqui como: aquilo que estamos acostumados a ouvir, dizer, fazer enquanto docentes - especialmente no que diz respeito a pensar a experiência vivida como'acúmulo intacto' ou um 'estar pronto' que, geralmente acomoda - para que dali pudessem se produzir outras possibilidades de pensá-la. Trata-se de uma escrita diagrama que, incita a docência a vazar por entre as brechas do arquivo que a delimita, inaugurando neste movimento outras tantas maneiras de estar docente.

DOS CONCEITOS ABORDADOS: SOBRE O QUE NOS DELIMITA E O QUE NOS FAZ VAZAR...

Os conceitos de arquivo, diagrama e fora que buscamos operar nesta escrita, para pensar a docência e o modo com que nos produzimos docentes, trazem para a discussão outros conceitos e termos que se enleiam a eles, como: saber, poder, resistência e dobra. Comecemos, então, nossas andanças por entre esse emaranhado a partir do questionamento: Nossas escolhas são pessoais?

Diríamos que talvez não tanto quanto imaginamos. Estamos embebidos numa época histórica, da qual surgem as condições de emergência de nossas escolhas. Há, portanto, saberes, estratos, que compõem a superfície 
que habitamos. Há arquivos que determinam nossas escolhas, somos mais arquivados do que arquivamos.

$O$ arquivo é "a lei do que pode ser dito, o sistema que rege o aparecimento dos enunciados como acontecimentos singulares" (FOUCAULT, 2008, p. 147). É o sistema que determina que enunciados permanecerão em cena e quais desaparecerão. "É aquilo que fora de nós nos delimita"(FOUCAULT, 2008, p. 148), ou seja, é de dentro de suas regras que falamos e vemos. Estamos embebidos numa época histórica, que determina as condições de emergência de nossas escolhas: do que dizemos, ouvimos e vemos.

Assim sendo, o arquivo é um estrato, uma lei, que não se modifica se não agir sobre ele uma força que o faça modificar-se. O arquivo precisa ser provocado para poder assumir outro posicionamento e ditar outras leis a respeito do que pode continuar ou não.

Audiovisual, o arquivo é formado por enunciados e visibilidades, pelo dito e pelo visto, cada qual mantendo sua heterogeneidade. Há, entre estes, ataques e entrecruzamentos que produzem a verdade, a cada vez, com o que é possível dizer e ver. Há também uma pressuposição recíproca, mas não correspondência. Como afirma Levy (2011), a partir de Foucault, podemos dizer o que vemos, mas jamais isso dará conta do que estamos vendo, e por mais que tentemos dar a ver o que dizemos, através de comparações ou metáforas, isso não torna visível o que dizemos.

A combinação entre o visível e o enunciável mantém ambos em sua diferença, em sua heterogeneidade, produz assim uma não relação, já que a combinação deles não resulta em uma síntese, mas sim em aliança, encontro, afetos (LEVY, 2011). Esta não relação produz estratos e o "estratificado não é o objeto direto de um saber que surgiria depois, mas constitui diretamente um saber" (DELEUZE, 2006b, p. 81). O saber é, portanto, um estrato composto do que é visto e dito e, como o visto e o dito se mantêm em sua diferença, há entre eles um intervalo que os distanciaria, um vazio no qual os dois "trocariam suas ameaças" (DELEUZE, 2006b, p. 77), uma dimensão informe que daria conta da estratificação e modificação de ambos.

É como se o arquivo fosse atravessado por uma grande falha, que põe de um lado a forma do visível, de outro a forma do enunciável, ambas irredutíveis. E é fora das formas, numa outra dimensão, que passa o fio que costura uma à outra e ocupa o entre-dois (DELEUZE, 1992, p. 121).

Assim, nossas escolhas, na superfície que habitamos, podem tanto se dar a partir do que está compondo um estrato, reforçando um saber, como 
podem ocupar esta abertura, provocando-a a se modificar inaugurando outros saberes que ainda estão sem forma.

Há estratos (saberes) que compõem a docência e o arquivo vai compondo estes estratos com o que é possível ver e dizer a cada vez. Estes saberes não são somente científicos, e se produzem em diferentes instâncias que envolvem a docência. Os saberes não são criados em laboratórios e impostos à sociedade, mas sim são produzidos (criados, reafirmados) coletiva e anonimamente, por todos que compõem o social. Embora não sejam pessoais, também não decorrem de uma imposição vertical. Os saberes se estratificam e se modificam em meio a lutas, combates e capturas. Vamos nos tornando docentes em meio àquilo que é possível ver e dizer a cada vez. O visto e dito da/na docência produz docência ao mesmo tempo em que é visto e dito.

Não cremos, entretanto, que os estratos sejam desnecessários ou que sejam um fardo inútil, porém pensamos que é necessário que eles sejam constantemente movimentados, recriados, para que não nos endureçam a ponto de impedir a locomoção. Como saber o momento de provocar uma rachadura nos estratos? Entendemos que as sensações de desencantamento, de tédio ou de inércia são suficientes para que saibamos que este momento chegou, mas vale lembrar que às vezes é necessário um esforço para perceber o tédio, o desencantamento e a inércia que nos endurecem.

Mas como produzir esta rachadura? Como abrir outras possibilidades de vida? O que pode provocar o arquivo a fazer funcionar outras regras e leis?

Se há um intervalo que separa o ver e o falar, o que o habitaria? 0 que costuraria uma forma a outra?

O que provocaria a formação de outros modos de ver e falar a cada vez? O que provocaria a docência a se diferenciar de si mesma a cada vez? O que o fora, o poder e o diagrama teriam a ver com isso?

A discussão, a partir destas questões, dirige se agora para o diagrama, uma dimensão informe, onde nada 'é'. Um composto de virtualidades', relações de força, que se atualizam no arquivo, e que só tomam forma ao se atualizarem no arquivo. $O$ informe que mistura matérias e funções, conteúdos e expressões, o ver e o dizer, de modo a produzir estratos e também mutações. Relações de força que habitam o vazio entre o ver e o dizer, entre o visto e o dito, produzindo sempre outras maneiras de dizê-lo e vê-lo.

A disjunção das formas é habitada, portanto, pelo diagrama, pelo informe, pelo poder diagramático que costura uma forma a outra. O diagrama assegura a relação entre o visível e o enunciável, e ali nos deparamos também 
com a relação poder/saber. Se o saber consiste no entrelaçamento do visível e do enunciável,

o poder é sua causa pressuposta, mas, inversamente, o poder implica o saber como a bifurcação, a diferenciação sem a qual ele não passaria a ato. Não há relação de poder sem constituição correlata de um campo de saber, nem saber que não suponha e não constitua ao mesmo tempo relações de poder (DELEUZE, 2006b, p. 48).

Um pressupõe o outro. Necessitam um do outro para que o processo de estratificação e mutação ocorra, e para que seja possível ver e falar a cada vez de outra maneira. O poder é composto por relações de força, ele se espalha no social, horizontalmente, agindo junto ao saber (composto por relações de formas), fazendo-o funcionar sob suas regras. Ele incita também resistências que, enquanto dobra deste poder, germinariam outros diagramas, ocasionariam, portanto, mudanças. O diagrama, as relações de força do poder se atualizam, ou seja, tomam forma no arquivo audiovisual. As formações históricas, os estratos, remetem, portanto, a um diagrama de forças que é o seu a priori histórico (LEVY, 2011). Mas de onde vêm os diagramas? Estas relações de força que sugerem outra composição, outra ordem? Este virtual que se atualiza no arquivo?

De um caos chamado 'fora' - O fora (fora do poder, fora do saber) "é o reino do devir, uma tempestade de forças, o não estratificado, o informe, um espaço anterior, de singularidades, no qual as coisas não são ainda" (LEVY, 2011 , p. 83). Seria a partir do pensar que chegaríamos ao lado de fora. Segundo Deleuze (2006b, p. 93-94), "pensar é chegar ao não estratificado. Ver é pensar, falar é pensar, mas o pensar opera no interstício, na disjunção entre ver e falar". É a partir desta conexão com o fora que a resistência ao poder, ocasionada pelo pensar, germinaria outro diagrama - um princípio de ordem em meio ao caos (fora) - que viria operar mudanças naquilo que vemos e dizemos e, assim, produzir outras possibilidades de vida.

Levy (2011) diz, de uma experiência do fora, que estaria relacionada ao pensar e também à arte, que é uma experiência que acontece quando há "uma violência que nos tira do campo da recognição", uma violência que nos lança ao imprevisível, "onde nossas relações com o senso comum são rompidas, abalando certezas e verdades" (2011, p. 100). É uma experiência na qual o pensar e a arte, ambos agem como formas de resistência, na qual percebemos a urgência de modificar aquilo que não toleramos mais, produzindo outras possibilidades de vida, "não possibilidades previamente 
imaginadas que deveriam simplesmente ser efetivadas, mas possibilidades que são inauguradas no próprio processo de mutação" (LEVY, 2011, p.100). Resistir nada mais é que dobrar a força, fazer com que ela se afete, ao invés de acabar com ela. É produzir com o fora um lugar para habitar, no qual é possível viver, pois o fora enquanto um caos pode nos arrastar para uma linha de morte. Uma vez atingido o fora, é preciso produzir uma dobra, produzir um dentro no fora, tornar o fora vivível, e isso diz respeito ao processo de subjetivação, a inventar, a cada vez que nos lançarmos ao fora, outra dobra - outra possibilidade de vida.

O diagrama opera, portanto, ao mesmo tempo, as singularidades de poder e as singularidades de resistência. Deleuze afirma que "as relações de poder se conservam por inteiro no diagrama, enquanto as resistências estão numa relação com o fora, de onde os diagramas vieram" (2006b, p. 96). $O$ poder se atualiza num saber que faz ver e falar, e a resistência, em contato com o fora, germinaria outro diagrama, que por sua vez se atualizaria em outras maneiras de ver e falar, produzindo assim diferenças.

Imagens e palavras, o audiovisual e o arquivo são atravessados por um "entre" que é habitado por um diagrama informe, nascido do fora, que os faz tremer e se insultar, e que também os costura, mantendo-os na heterogeneidade que lhes é própria, produzindo mais camadas que fazem ver e dizer a cada vez de outra maneira.

O que pode a docência ao habitar o interstício que se aloja entre o dito e o visto? Ao habitar o vazio que se aloja naquilo que dizemos e vemos na/da docência?

Segundo Corazza, é somente neste vazio que

é possível produzir abalos; provocar mudanças no que somos capazes de ver e de dizer; dar alegres cambalhotas; radicalizar nossas relações com o poder e o saber; partir as linhas; mudar de orientação; desenhar novas paisagens; promover outras fulgurações. Enfim, artistar, inventando novos estilos de vida e, portanto, de práticas (CORAZZA, 2007, p. 122).

Assim, buscamos andarilhar pela parte vazia da docência, recolhendo os afetos em nós disparados pelas flechas lançadas por seus enunciados e visibilidades em batalha e - com o pensamento, fotografias e uma experimentação artística - intentamos lançá-los a outro lugar, para fazê-los variar, pegar delírio. Buscamos resistir, entrar em conexão com um fora, fazer brotar dele outros diagramas, produzindo outras possibilidades de ver e dizer a docência, e deixando ainda, em meio a eles, vazios, com batalhas ainda por 
vir, onde quem se aventurar a habitá-los possa também pegar no ar uma de suas ferramentas de batalha e lançá-la novamente ao fora, para poder inventar as suas. Buscamos pensar a docência que se produz a cada vez em meio a essas batalhas cotidianas (entre o ver e o falar), que se diferencia de si a cada flecha lançada a um fora e que produz a cada dobra uma morada provisória.

DOS ELEMENTOS COM OS QUAIS BUSCAMOS TRANSBORDAR A DOCÊNCIA...

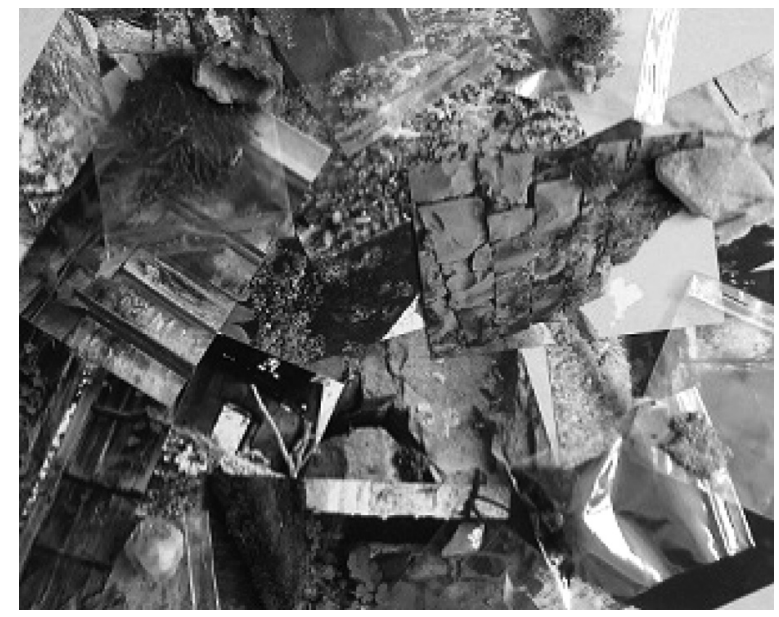

Figura 1- Elementos de nossas vivências solicitados a compor a pesquisa.

Fonte: Acervo pessoal.

Os elementos trazidos para pensar a docência são entendidos não como algo que vem para ilustrar a escrita ou para explicá-la, mas sim são pensados como disparadores, como algo que violenta o pensamento a pensar (LEVY, 2011). Não intentamos aqui falar deles, mas sim com eles, de modo que espaços vazios também sejam possíveis, onde o leitor possa também experimentar e produzir singularmente outras relações e possibilidades (HERNÁNDEZ, 2013). São vazios que não intentam ser preenchidos, apenas habitados por quem tiver interesse em experimentá-los (ou for arrastado para experimentá-los), numa conexão com o que lhe toca, com o que lhe encanta ou incomoda, com o que lhe movimenta, com o que lhe incita a vazar e a produzir outras possibilidades.

Dos afetos recolhidos na pesquisa escolhemos alguns para compor a escrita que segue, de modo a pensar algumas questões acerca da 
docência que dialogam com os conceitos elegidos neste artigo. Em especial, abordaremos a experiência docente que se produz a cada vez e também o imprevisível que ronda o que planejamos enquanto docentes, fazendo-o escapar em direções inesperadas.

\section{DAS EXPERIENNCIAS QUE SE PRODUZEM A CADA VEZ...}

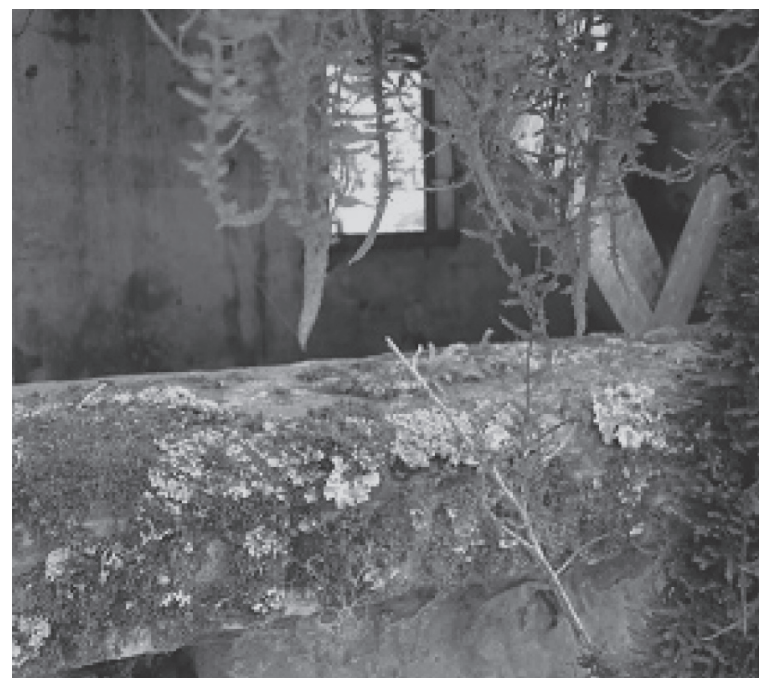

Figura 2 - Fotografia de casa abandonada (Nova Palma-RS, 2013).

Fonte: Acervo pessoal.

O que uma casa abandonada pode dizer de nossa experiência docente? Onde está nossa experiência docente? No tempo de regência de classe? Em nossa formação acadêmica? Nas conversas de bar? Nos trajetos que percorremos diariamente?

Bem, começamos abordando o que entendemos como experiência a partir dos autores que convidamos a esta escrita. A experiência é percebida aqui não como algo que já foi algo que se acumula (pelo menos enquanto algo que se acumula e permanece como foi), pois ela acontece, ela está sendo. Se a experiência é o passado que se atualiza e se prolonga no futuro, é também um presente que sempre escapa tão rápido que não dá tempo de checar qual o melhor caminho para atender às necessidades que se encontram nela. Por isso, pensamos ser impossível localizar nossa experiência como docentes, pois ela não se acumula tal qual a forma como a vivemos, ela apenas se prolonga em 
várias direções, se atualizando em outras maneiras de se insinuar, produzindo outras máscaras, outras tantas docentes, não sendo possível mencionar uma única, nem tampouco reuni-las num mesmo todo homogêneo de uma experiência acumulada. As experiências já vividas nos acompanham, mas funcionam como disparadores de uma nova direção, não servindo, assim, às vivências futuras como algo que venha dizer exatamente o que fazer, pois cada situação que as solicita é singular. Estas experiências vividas são, assim, movimentadas para não permitir que fiquemos em repouso por muito tempo no determinado docente que vestimos. Nesta perspectiva, não cabe a busca da experiência como acúmulo, pois ao buscarmos a experiência vivida (a que nos acompanha virtualmente) ela já se tornou (se atualizou em) outra experiência, pois a situação que a solicita é outra, nós mesmos já não somos aqueles de antes.

Como estar suficientemente pronto para a docência? Como estar pronto para algo que é habitado sempre de maneira diferente? Por outras pessoas, outras singularidades, outras paixões, outros afetos? Em que, a cada vez, a cada recombinação, outro docente em nós é solicitado, ou necessário?

Sentimo-nos prontos, geralmente, quando algo se fixou em nós, ou quando nós nos fixamos em algo, ou o damos como suficiente. Mas se tudo muda, e as situações que enfrentamos são diferentes, de que vale a experiência vivida anteriormente? Como podemos buscar, na docência anterior, o que a docência atual solicita? Como torná-la potência?

Podemos torná-la uma experiência atual, problematizando-a, atualizando-a conforme as solicitações presentes, compondo com ela e com o que, a cada vez, se enleia em sua superfície. Não se trata, assim, de abandonar as vivências anteriores, mas sim de experienciar estas vivências enredadas à situação presente e aos afetos que emergem nela. Trata-se de um constante produzir-se docente, de uma abertura ao fora, para inventar, a partir dele, outros diagramas que intervenham no arquivo que nos delimita, estremecendo os já ditos e os já vistos e inventando outras maneiras de estar docente, ou quem sabe apenas borrar a maneira com a qual estamos acostumados a ver a docência, e fazer gaguejar o já dito e as verdades que se julgarem eternas.

Nesta perspectiva, não cabe, portanto, a busca da experiência como acúmulo - uma experiência que se mantém intacta tal qual a vivemos, num acúmulo que se produz apenas enquanto diferença de grau - mas, sim, como uma experiência que se inaugura, sempre, no próprio movimento, no emaranhamento com o presente. Dá-se uma mudança de natureza na qual as 
vivências passadas se diferenciam de si mesmas na experiência que se produz a cada vez, a partir dos encontros com as situações presentes. Conforme afirma Levy, a experiência, enquanto algo que se abre ao fora, "é o que está sempre se fazendo - o novo por excelência" (2011, p. 137), não é histórica, mas sim devir. É uma prática de resistência, de colocar sob suspeita o que tomamos por verdade, é dobrar a força, devir outro, inventar outros de nós mesmos.

Há sempre forças desconhecidas (vindas do fora) à espreita de um vacilo do arquivo para poder adentrar a fissura que o atravessa e inventar outras possibilidades de vida.

\section{DOS TRANSBORDAMENTOS QUE NÃO SUPORTAM SER CULTIVADOS...}
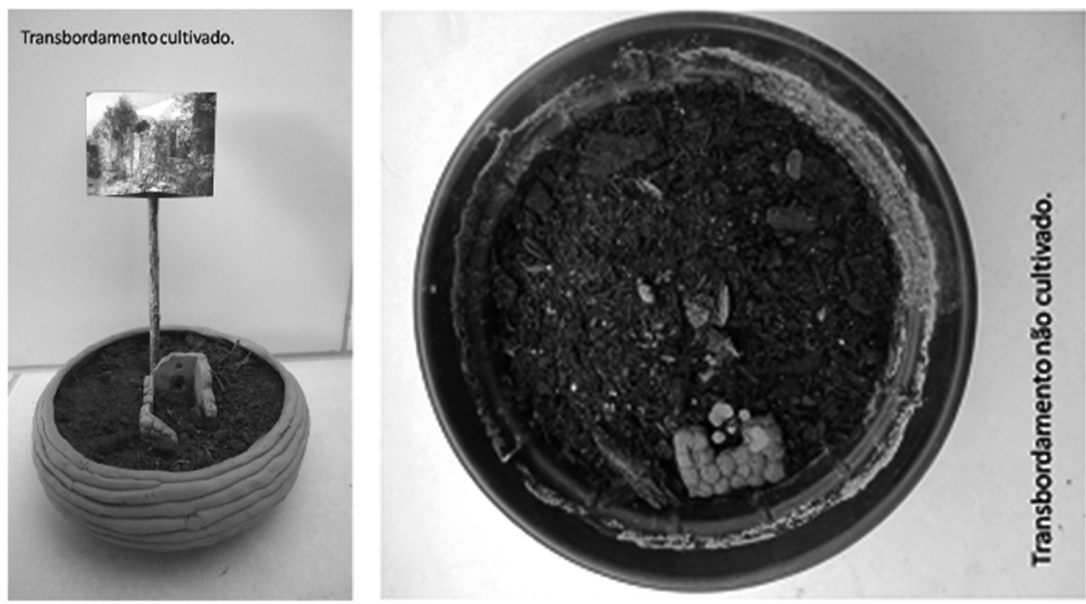

Figura 3 - Fotografias da experimentação artística "Tentativa frustrada de cultivar transbordamentos", 2013.

Fonte: Acervo pessoal.

Outro elemento que nos disparou à escrita, provocando nosso pensar a docência, foi a experimentação artística - "Tentativa frustrada de cultivar transbordamentos". A experimentação consistiu em coletar uma porção de terra nas proximidades de algumas casas abandonadas e colocá-la em potes com casinhas de cerâmica (queimada), na expectativa de que nascessem ali plantas por conta própria - como comumente nascem quando não as desejamos. Nesta experimentação levamos a primeira lição do transbordamento: ele não suporta ser cultivado. No pote em que desejávamos que ocorresse o nascimento de plantas da própria terra, não aconteceu; num outro pote abandonado, no qual 
havíamos posto fora um fragmento da casinha, nasceu uma plantinha bem próxima a ele. Nesta experimentação artística, inaugurou-se, em seu próprio movimento, a problematização sobre aquilo que escapa ao que cultivamos. Já afirmava Miller, citado por Deleuze e Guattari:

É talvez a erva daninha aquela que leva a vida mais sábia [...] A erva existe exclusivamente entre os espaços não cultivados. Ela preenche os vazios. Ela cresce entre, e no meio das outras coisas. A flor é bela, o repolho útil, a papoula enlouquece. Mas a erva é transbordamento (MILLER s/d apud DELEUZE; GUATTARI, 1995, p. 29-30).

Entretanto, sejamos prudentes e não nos lancemos simplesmente ao outro extremo. Não se trata, pois, de não planejarmos nada, não cultivarmos nada, mas, sim, de estarmos à espreita do que cresce no meio ao que havíamos planejado com tanto cuidado, do que escapa ao nosso controle, do que escapa ao que estamos acostumados a esperar, ao que já está dado.

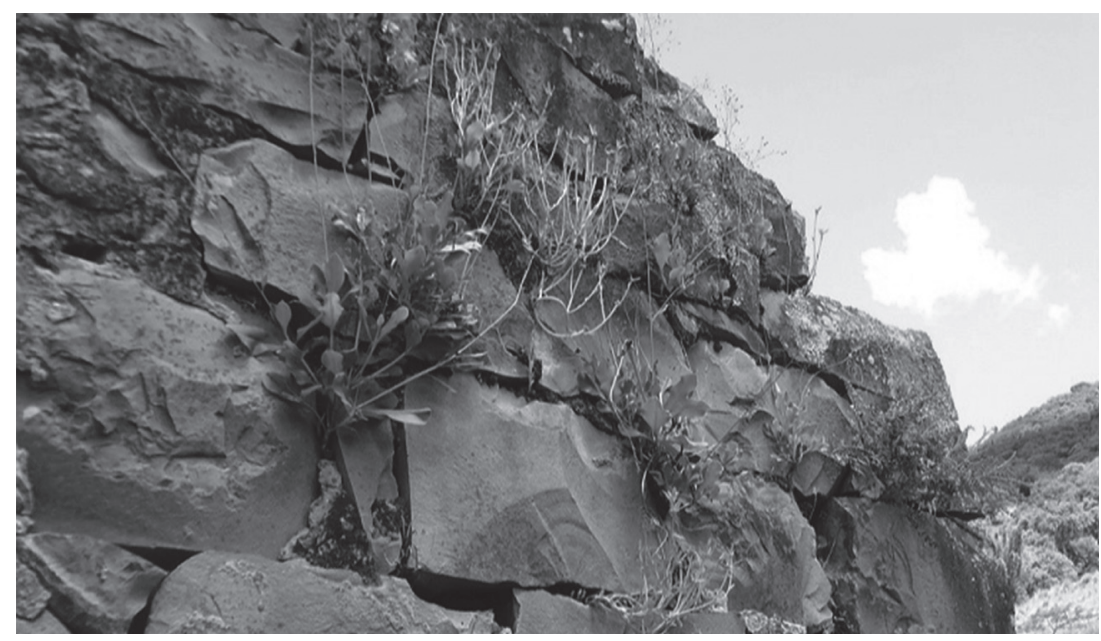

Figura 4 - Fotografia de casa abandonada (Val de Buia-RS, 2013).

Fonte: Acervo pessoal.

Em uma aula, por exemplo, podemos até planejar os elementos que vão participar da mesma, podemos até objetivar que uma experimentação ' $x$ ' aconteça, mas não temos o controle de como o outro irá experimentar nossa aula, ou, então, de que outros elementos serão necessários acrescentar devido às circunstâncias do momento, ou de quais outros elementos serão acrescentados pelos próprios estudantes a esta composição. O imprevisível está 
sempre a rondar o que planejamos, e podemos deixá-lo passar despercebido, podemos ignorá-lo, mas também podemos utilizá-lo como disparador para outras direções, tão ou mais produtivas do que aquelas que planejamos.

Preparamo-nos para cada aula e é necessário que o façamos, mas não podemos deixar que este planejamento se feche a ponto de agir como uma viseira que não nos deixe ou nos faça ignorar os imprevistos que o atravessam. O que cresce sem supervisão em meio ao que cultivamos pode nos arrastar para direções impensadas, pode ser o germe que inaugura outras possibilidades de vida.

O que podemos aprender com Foucault quando ele propõe uma ética enquanto um "constante descompromisso com as formas constituídas" (LEVY, 2011) que resista aos códigos do saber e do poder e invente outros modos de existência?

Que nossas verdades são construções provisórias, que o que escapa ao que conhecemos ou esperamos pode agir como uma abertura para o fora. Resistir é entrar em conexão com o fora, com o que nos tira do campo de recognição e nos permite inventar, a partir de dobras desse fora, outras possibilidades para o que tínhamos planejado anteriormente.

Que é necessário estar à espreita das ervas daninhas que insistem em crescer em meio ao que desejamos (ou nos ensinam a desejar), não para aboli-las, mas para aprender com elas a transbordar aquilo que nos conforma, aquilo que nos acostuma a 'ser' e aquilo que endurece o nosso movimento de 'estar', de vir a ser.

Para finalizar ESTA ESCRITA: DOS VAZIOS HABITADOS E POR HABITAR...

Foucault e Deleuze nos provocaram a pensar, a partir dos conceitos de arquivo, diagrama e fora, que, sim, há um arquivo que nos delimita enquanto docentes, com tudo que nos é possível ver e dizer, mas há também neste arquivo um intervalo, um vazio, no qual podemos habitar com resistências que nos lancem ao fora, onde podemos inventar outros tantos diagramas que se atualizem, ganhem forma em outras maneiras de estar docente.

Nesta escrita, para além de responder ao questionamento: Como varrer a figuração docente e fazer surgir dela outra forma de natureza diferente, que intervenha no que é costumeiro e a faça transbordar em outras direções? tentamos operar esta varredura, principalmente no que diz respeito à ideia de experiência docente como algo homogêneo, que se dá pelo acúmulo intacto de vivências, seja através da atuação como docente ou de formação acadêmica para a docência. Diríamos, a partir dos autores que trabalhamos aqui, que 
não se trata de 'uma' experiência, mas sim de uma cartografia sem fim, sendo produzida por experiências inauguradas a cada encontro, a cada solicitação presente. Não pensamos assim em uma docência que vai se reafirmando numa única direção, mas sim numa docência que escapa e se produz, a partir dos encontros que a afetam em meio à vida.

Sim, em meio à vida, pois os afetos que nos diferenciam de nós mesmos podem se dar em qualquer situação ou elemento cotidiano: uma obra artística, um filme (que diz ou não da docência), uma música, uma casa abandonada, uma plantinha que cresce em uma rachadura, enfim, qualquer coisa pode servir de disparo para pensar a docência, desde que a afete e a provoque a diferenciar-se de si.

Nesta escrita as fotografias de casas abandonadas e a experimentação artística "tentativa frustrada de cultivar transbordamentos", bem como os conceitos abordados agiram como disparadores para pensá-la. O que pensamos com eles? Que podemos habitar, assim como as ervas daninhas, o vazio que se instala entre o dito e o visto na docência. Que podemos resistir e arrastar o já dito e o já visto para o fora, embaralhá-los ao informe e então trazer outras coisas para batalha, coisas ainda informes que, aos poucos e silenciosamente, vão produzindo outras maneiras de ver e dizer a docência, e consequentemente outras maneiras de estar docente, de experienciar a docência.

Estes vazios vão sempre existir. Portanto, o que muda é a nossa relação com eles. Podemos cortar as ervas daninhas que insistem em crescer em seu interior, impossibilitando assim que outros modos de vida se desenvolvam, mantendo tudo em sua ordem. Ou, então, podemos aprender com elas a forma de habitar este vazio de modo que seja possível inventar e experimentar outras possibilidades de vida.

Artigo recebido em: 13/08/2014 Aprovado para publicação em: 01/10/2014

\section{INVENTING DIAGRAMS TO OVERFLOW THE ARCHIVE THAT FRAMES TEACHING}

ABSTRACT: This text proposes to think teaching through the concepts of "archive", "diagram" and "outside", which would suggest approaching a teaching practice which is always escaping and differentiating itself from itself in every encounter that affects it along its wanderings through life. The way this study develops is in accordance with our wanderings and with what we find, carry away, and sometimes lose along 
the way. It is also in accordance with the affections which trigger us to think teaching from places other than that of just a teaching performance. Thus, some photographs and an artistic experimentation permeate this writing, affections that are convoked to dialog with the concepts of archive, diagram, and outside, which out of this meeting produce crossings in teaching, making it overflow in other directions.

Keywords: Archive. Diagram. Outside. Teaching.

INVENTAR DIAGRAMAS PARA TRANSBORDAR EL ARCHIVO QUE DELIMITA A LA DOCENCIA

RESUMEN: El propósito de este texto es pensar la docencia partiendo de los conceptos de archivo, de diagrama y extramural, lo que nos sugiere pensar en una docencia que escape permanentemente y se diferencie de sí misma a cada encuentro que le afecte en su devenir por la vida. La forma como este texto se desarrolla se produce a partir de nuestro diario caminar y de lo que en él hemos encontrado, recogido y a veces perdido. Ocurre a partir de los afectos que nos motivan a pensar la docencia desde otros puntos de vista que no son solamente el de una actuación del maestro. De esta forma, el texto es permeado por algunas fotografías y una experiencia artística, afectos que son invocados para dialogar con los conceptos de archivo, diagrama y extramurales, produciendo a partir de este encuentro, transversalidades en la docencia y, así, desbordándola en otras direcciones.

Palabras claves: Archivo. Diagrama. Extramuro. Docencia.

\section{NOTA}

1) O virtual é entendido, aqui, a partir de Deleuze (2006a; 1999), como algo sem forma, algo ainda por vir, que só toma forma ao se atualizar. Este processo de atualização, produção de um atual, é sempre criação, ou seja, produção de uma diferença, pois o atual jamais se assemelha à virtualidade que atualiza. Atual e virtual andam sempre juntos, são duas faces de um mesmo objeto, ou seja, tudo que é atual, que possui forma, que é dito e visto, carrega consigo uma parte virtual, a parte não resolvida das coisas que permanece sempre aberta a outras possibilidades.

\section{REFERÊNCIAS}

CORAZZA, S. M. Labirintos da pesquisa, diante dos ferrolhos. In: COSTA, M. V. (Org.). Caminhos Investigativos, I: novos olhares na pesquisa em educação. 3. ed. Rio de Janeiro: Lamparina editora, 2007. p. 103-127. 
DELEUZE, G. A vida como obra de arte. In: . Conversações. Tradução de Peter Pál Pelbart. São Paulo: Editora 34, 1992. p. 118-126. . Bergsonismo. Tradução de Luiz B. L. Orlandi. São Paulo: Editora 34, 1999. . Diferença e Repetição. 2. ed. Tradução de Luiz Orlandi e Roberto Machado. Rio de Janeiro: Graal, 2006a.

. Foucault. Tradução de Claudia Sant'Anna Martins. Revisão de tradução por Renato Ribeiro. São Paulo: Brasiliense, 2006b.

DELEUZE, G.; GUATTARI, F. Mil Platôs: capitalismo e esquizofrenia. v. I. Tradução de Aurélio Guerra e Célia Pinto Costa. Rio de Janeiro: Editora 34, 1995.

FOUCAULT, M. A Arqueologia do Saber. 7. ed. Tradução de Luiz Felipe Baeta Neves. Rio de Janeiro: Forense Universitária, 2008.

HERNÁNDEZ, F. A pesquisa baseada nas artes: propostas para repensar a pesquisa educativa. In: DIAS, B.; IRWIN, R. L. (Org.). Pesquisa Educacional Baseada em Arte: a/r/ tografia. Santa Maria: Editora da UFSM, 2013. p. 39-62.

LEVY, T. S. A Experiência do Fora: Blanchot, Foucault e Deleuze. Rio de Janeiro: Civilização Brasileira, 2011.

Francieli Regina Garlet é graduada em Artes Visuais (Licenciatura em Artes Plásticas), pós-graduada em TIC Aplicadas à Educação e mestre em Educação pela Universidade Federal de Santa Maria. Atualmente é doutoranda em Educação, membro do Grupo de Estudos e Pesquisas em Arte, Educação e Cultura (GEPAEC) e do srupo Pesquisa em Arte: Momentos Específicos.

E-mail: francieligarlet@yahoo.com.br

Marilda Oliveira de Olivelra é professora do Programa de Pós- Graduação em Educação da Universidade Federal de Santa Maria, RS. Coordenadora do GEPAEC - Grupo de Estudos e Pesquisas em Arte, Educação e Cultura e Editora da Revista Digital do Laboratório de Artes Visuais.

E-mail: marildaoliveira27@smail.com 